\title{
A Postdigital Future for Music Education: Definitions, Implications, and Questions
}

\author{
Ann Clements \\ Pennsylvania State University
}

The term postdigital has been used by various disciplines to draw attention to the changing relationship between digital technology and human social and artistic practices. This article explores multiple definitions of the term postdigital from the disciplines of music, visual art and design, architecture, business, marketing, media and film studies, and education. It then argues that the use of this term reflects a paradigm shift in these fields. This shift has implications for the future practice of K-12 music education including the impact of digital cleanliness and ease of production, the growing hybridity of digital and traditional music making, and the influence of digital technology on human artistic practice.

Keywords: music education, music making, postdigital, digital, technology, media, arts, sociocultural, humanism, societal change, future.

\section{Music "Devolution"}

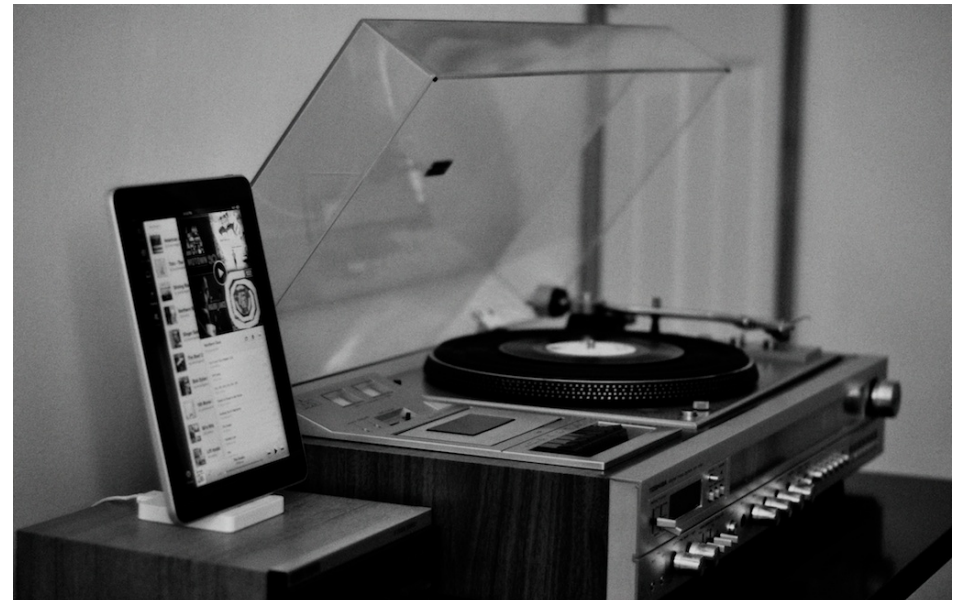

How times have changed.

You can deny it as much as you want, but the music industry has, in a sense, gone to shit - it's been a major dumbing down for the past decade or so. We have stuff like iTunes and Spotify to thank for that. Am I hating these music services? No, I love my iPhone $4 \mathrm{~S}$ and I'm an avid user of Spotify, but they still caused a vast change in the industry in terms of splitting up once com-

(C) Ann Clements 2018. The content of this article is the sole responsibility of the author. The ACT Journal and the Mayday Group are not liable for any legal actions that may arise involving the article's content, including, but not limited to, copyright infringement. 
plete albums into single releases. I'm a person who appreciates the entire album on an LP, as it's how the artist originally intended.

Vinyl to me is always going to be the king of all formats in terms of sound quality, overall music enjoyment and shelf life. The iPad is okay, but it's nothing more than some digital signals working via Wi-Fi to stream the music from a Spotify Server. To me vinyl can be far more appreciated.

Deep down I know the music industry is kicking themselves, if they'd have stuck with vinyl it would have not only provided a crisper sound (as development would have been on going with quadrophonic records etc.). It would have also prevented music piracy from getting to the extent it has currently, because let's face it, it is quite difficult to record a vinyl in high quality and then to spend time compressing to a useable size. This area is generally a hobbyist's thing. The average consumer would have most likely stuck with making personal use mix tapes for the car.

Vinyl you rule.

My oldest Vinyl in my collection was pressed in 1949 it's a Dixieland Jazz album and it plays without skipping or jumping perfectly fine. I have CD's what are from 1990/91 and some of the silver has warn away making them in essence useless. It's not like the vinyl has been terribly well look after either. This album spent its time being played on a radiogram with a heavy tone arm and then stored for the past 25 years in a garage which half flooded almost every year.

LOL

Peace.

(A photo essay by Ryan J. Nicholson. Published to Flikr.com on May 28, 2012, used by permission)

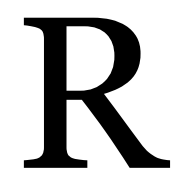

yan J. Nicholson's photo essay, published in 2012 to the photography sharing social media platform Flickr, illustrates the rift between "digital" and "postdigital" paradigms. The photograph symbolically captures two forms of music players placed side-by-side, a turntable and a digital tablet that is displaying a music playlist.

The author asserts his preference for vinyl, but he does not show complete disdain for digital recordings. He admits that he uses and enjoys digital media, and he laments that the industry went digital since there are characteristics of vinyl that cannot be replicated digitally, at least at a consumer level. He recognizes that digitalization of the music industry not only changed the recording industry's business model and the sound quality of and access to commercially available music, but also the creative processes of making new music, such as in-

Clements, Ann. 2018. A postdigital future for music education: Definitions, implications, and questions. Action, Criticism, and Theory for Music Education 17 (1): 48-80. doi:10.22176/ act17.1.48 
dividual tracks taking priority over complete albums and the increased use of digital or digitally enhanced instruments and editing. This essay highlights, at least at a consumer level, that the changes brought about through digital technology use are not simply at the surface but are deeply rooted in what some believe to be unnecessarily disruptive practices that are not always closely investigated for both need and desire.

This complicated intertwining of the use and appreciation of older technologies alongside the access to and ease of use of digital technologies brings to light many important questions concerning how individuals and societies come to terms with our rapidly changing or changed relationships with technologies in music, music education, and the arts. It also warrants discussion concerning the role of digital technology in an era in which digital technology use has become less unique or novel while, simultaneously, that use is open to increased criticism through aesthetic and social lenses.

The history of digital technology use in American music education has been documented in numerous journals, books, and professional presentations (e.g. Bauer 2014, Haning 2016, Rudolph 2004, Watson 2011, Webster 2011, Williams and Webster 2006). Much of the technology-based research in music education focuses on digital tools and their application (Albert 2015, Bolden 2013, Nart 2016, Reyher 2014, Riley 2013, Williams 2014), teacher training (Haning 2016, Nart 2016), and potential impacts on learning (Portowitz, Peppler, and Downton 2014; Webster 2016). These papers have contributed positively to thoughtful implementation of digital technologies in the music classroom. There is also a growing number of music education studies that explore technology through a theoretical lens (e.g. Bauer 2014; Clements 2016; Crawford 2013; Ruthmann, Tobias, Randles, and Thibeault 2015; Thwaites 2014). Even as digital technology was coming of age in the early twenty-first century, Madsen (2000), in Vision 2020: The Housewright Symposium on Music Education, declared that as a field we need to be both proficient and knowledgeable with regard to technological changes while "recognizing the importance of people coming together to make and share music" (219-20).

In this paper, I will explore the broad impact that changing digital technologies have on human perspectives and engagements within the arts and question how these perspectives may impact music education in what some have called a postdigital era. This article explores the term postdigital by focusing on its vari-

Clements, Ann. 2018. A postdigital future for music education: Definitions, implications, and questions. Action, Criticism, and Theory for Music Education 17 (1): 48-80. doi:10.22176/ act17.1.48 
ous definitions and uses. It will explore cultural assumptions of digital technology use and provide three organized constructs based in postdigital literature outside of music education that contain conceptual elements that bind them together. The content for these constructs come from a variety of literature sources across multiple fields. These constructs are provided to represent groups of assumptions and perceptions that are present in literature and do not, necessarily, represent the opinions of the author. These constructs are entitled "digitotalitarianism," "digital expansion," and "digital-cultural hybridity." Each construct concludes with the author applying the questions raised within that construct to the field of music education and asks questions intended to invoke the reader's critical thinking, curiosity, and potential actions in regards to the topic.

\section{Defining the Postdigital Era}

Post-digital: a term that sucks but is useful. (Cramer 2014, para 6)

In 1998, Nicholas Negroponte, founder of the Massachusetts Institute of Technology Media Lab, stated in an article entitled Beyond Digital: "Face it-the digital revolution is over" (para 2). According to Negroponte technology was already beginning to be taken for granted. He predicted, "like air and drinking water, being digital will be noticed only by its absence, not its presence." Acknowledging that we are living in a digital age surrounded by technology, he believed that the most important and dramatic changes will not simply be the production of new technologies, but will appear as societal changes "in our lifestyle and how we collectively manage ourselves on this planet" (para 4-5).

The term postdigital era aims to move the conversation away from a focus on digital tools and their uses towards a focus on human engagement within a digital world, for better or worse. While practically unmentioned in music education scholarship, it has become an increasingly important, yet deceptive, concept in technology-based disciplines. Despite growing popularity of the term postdigital, no single discipline has solidified a definition of its meaning, use, and value across settings. The numerous, and sometimes contrary meanings ascribed with the term postdigital are apparent in scholarly, journalistic, and social media sources and within the application of the term to communities, events, and productions, most of which are deliberately organized to push societal thinking in

Clements, Ann. 2018. A postdigital future for music education: Definitions, implications, and questions. Action, Criticism, and Theory for Music Education 17 (1): 48-80. doi:10.22176/ act17.1.48 
opposition to digital endeavors and towards a relationship of materials to human engagement.

Part of the problem with term postdigital is that it implies that the digital revolution is over, as if digital technology no longer matters or is no longer being produced, which simply is not the case. This is particularly true for those who believe that there is no postdigital age, or at least not yet, and that we are simply in an unknown or untitled continuation of digital technology discovery and use.

A stumbling point for many when considering the postdigital era paradigm, is confusion concerning the term post-. Cox (2014) calls into question the use of this term in regards to other historico-philosophical noun prefixes from postmodernity to posthistoire. However, as Cramer (2014) argues, it may be more appropriate to consider the postdigital in association with other popular culture uses of post- rather than through historical ideological terms. Using the example of post-punk, Cramer emphasizes that the post-punk music movement continued in ways that were both punk and not punk. Similarly, post-colonialism may describe a time after colonization, yet to many, if not most (particularly indigenous populations), colonization never ends and continues to frame cultural perspectives forever. In science fiction, visions of post-apocalyptic life do not imply that the apocalypse is over, only that it has transformed surroundings indefinitely.

As the term postidigital era is intending to both simultaneously describe a current age and define a current social movement, it is by nature emerging and fluid. One way to account for this fluidity is to consider the term postdigital as a paradigm, allowing the complexity of this term to become organized and simplified in order to make certain fundamental assumptions about the nature of this phenomena and its potential impact on individuals and society (Ratcliffe 1983). Through the exploration of the term postdigital era as a paradigm, significant consideration can be given to the various ways in which practitioners (those who do or do not utilize digital technologies in particular ways) rationalize the effect of digital technologies on the human condition.

\section{The Digital Era}

It is challenging to define the postdigital era without some discussion of the term digital era. The digital era, also called the Information Age, the Computer Age, and the New Media Age, is defined as the time period starting between the $1950 \mathrm{O}$

Clements, Ann. 2018. A postdigital future for music education: Definitions, implications, and questions. Action, Criticism, and Theory for Music Education 17 (1): 48-80. doi:10.22176/ act17.1.48 
and the 1970s when analogue technologies became digitalized. Development of the Internet by the United States Department of Defense in the 1960s and the subsequent adoption of personal computers a decade later spawned what many have called the Digital Revolution.

The development of fiber optic cables and faster microprocessors accelerated the transmission and processing of information. The World Wide Web, used initially by companies as an electronic billboard for their products and services, morphed into an interactive consumer exchange for goods and information. The Internet has grown to become a world-wide broadcasting platform, a mechanism for information dissemination, and a medium for collaboration and interaction between individuals and their electronic devices without regard for geographic location, at least in those countries and communities that can afford access or have the freedom of access. Electronic mail (email), followed by social media and messaging have permitted near-instant exchange of information.

The digitization of information has had a profound impact on traditional media businesses, including newspapers, book publishing, the music industry, and more recently the major television and cable networks. As information is digitally instantiated, businesses across many industries have sharpened their focus on how to capitalize on these changes. Of perhaps greater importance than the effect of digital technology on commerce and the global economy, are the societal changes for those in developed countries who have access to digital information and have the required skills to use and contribute to digital knowledge. These societal changes include the creation, distribution, use, integration and manipulation of information for significant economic, political, and cultural activity.

Digital technology in American music education has resulted in a multitude of curricular, if not pedagogical, changes in the areas of creativity through improvisation, arranging, and composition (Abrahams 2015, Bolden 2013, Hoffman and Carter 2013, Tobias 2013, Webster 2016), experiences with diverse instruments (Williams 2014), notational writing and reading (Hansen and Milligan 2012, Riley 2013), and an impact on issues of accessibility (Nelson 2013, Rush 2015). Digital technology use has propelled these areas into new territory in terms of ease of process.

Yet, despite rhetoric and interest in the presence of technology in music classrooms, there remains questions concern the utilization of technology to facilitate learning outcomes (Dorfman 2008, Jassmann 2004, Ohlenbusch 2001,

Clements, Ann. 2018. A postdigital future for music education: Definitions, implications, and questions. Action, Criticism, and Theory for Music Education 17 (1): 48-80. doi:10.22176/ act17.1.48 
Reese and Rimington 2000) and the impact of technology in terms of the enhancement of musical experiences for students (Bauer 2014). The question remains whether it is an issue of use or something much deeper. Bauer (2014) points out that while technology is a tool that can be understood and utilized by teachers, that knowledge alone is not sufficient in insuring effective use. Determining the effectiveness of technological use will always present challenges; and we as a field have yet to fully consider the impact of digital technology on music teaching and learning within the complexities of the very human music classroom.

The contextual nature of classrooms and rehearsals do not lend themselves to easy recipes that will guarantee successful learning, with or without technology. The art and science of teaching by skilled educators involves making 'real time' instructional decisions, adjusting on the fly. The use of any teaching tool, including technology, requires the ability to consider that tool in light of students, learning outcomes, pedagogy, the classroom environment, and the tool itself. (Bauer 2014, para 1)

As Bauer indicates, the use of technology is not a "one size fits all" answer to long standing teaching and learning problems and questions, particularly given the messy nature of both teacher training and technological limitations. Due to the prevalence of digital technology in modern society, dialogues about its use in the music classroom must continue to move further away from simply an exploration of specific tools and their uses and towards a deeper research-supported understanding of the impact of digital technology on music making and doing and on being human in a digitally saturated world. A logical starting place is to determine what musical skills and knowledge are of most value as we progress beyond the novelty of digital technology use.

\section{Human Engagement and Technology}

Humans have been interacting with technology since the beginning of time. One definition of technology states that it is the "sum of the ways in which a social group provides itself with the material objects of civilization" (Hammond 2011, para 5). Fundamentally, technology is the application of scientific knowledge, making a process, or life itself, easier. Often thought of as machinery or equipment, it can also be a branch of knowledge of applied sciences or an industrial

Clements, Ann. 2018. A postdigital future for music education: Definitions, implications, and questions. Action, Criticism, and Theory for Music Education 17 (1): 48-80. doi:10.22176/ act17.1.48 
process, invention, or method. These definitions make technology both a thing and an ongoing action.

Bernard Stiegler is a French philosopher whose work attempts to describe the entanglement of technology, culture, and social change by invoking a non-linear evolutionary process described as epuphylogenesis. Within this process, human engagement with non-living things, such as digital interfaces and structures, creates relationships primarily based in memory that cause humans to be inseparable from the technologies they have experienced, even beyond individual lifetimes.

This "techno-logical memory" (Stiegler 1998, 177) within society is what we individually enter into through enculturation and acquired skill. Within this perspective, previous technology use creates a past for us that we continue into the future as our own. The degree to which people are enculturated and the ways in which that enculturation comes into being influences individuals' technology use, as well as contributes to larger societal definitions of the role of those technologies. According to Stiegler (1998) this implies that the impact that technology has on individuals and society, including cultural practices, may have a longer lasting effect on humanity than ever imagined, becoming a form of non-genetic, memory-based engineering that may be nearly inescapable by future generations.

As the postdigital era paradigm has been written about in multiple fields, there are differing definitions, interpretations, and supporting rationales. Yet, despite this lack of congruency, conversations surrounding perceptions of the postdigital era can be divided into three primary constructs without too much oversimplification, although some will certainly be present.

The first construct, or grouping, entitled Digitotalitarianism, is based on the movement away from digital technologies, sometimes back towards nostalgia and the analogue and at other times towards new humanistic directions. The second grouping entitled Digital Expansion is based on acknowledgment that the digital era is not over and that digital tools and technologies are playing an everincreasing role in society, and there is really no problem with that current trajectory. The third grouping entitled Digital Cultural Hybridity explores perspectives that intend to move society beyond digital tools and trends to, instead, focus upon broader sociocultural questions surrounding digital being.

Clements, Ann. 2018. A postdigital future for music education: Definitions, implications, and questions. Action, Criticism, and Theory for Music Education 17 (1): 48-80. doi:10.22176/ act17.1.48 


\section{Construct 1: Digitotalitarianism}

Information paints no picture, sings no song, and writes no poem. (Gregory 2014)

The term Digitotalitarianism, which I have created, intends to represent the resentfulness of digital technology use by certain artistic communities. This term, intended to be somewhat tongue-in-cheek, proposes to capture the refutation of digital technologies by those who feel subservient to its use. From this perspective, the pervasiveness of digital technology can be escaped by intentionally reverting to pre-digital art forms.

Florian Cramer, in his article What is Postdigital? (2014), echoes Nicholson's disillusionment with the digital by defining postdigital as "either a contemporary disenchantment with digital information systems and media gadgets, or a period in which our fascination with these systems and gadgets has become historical" (para 7). The disenchantment with the digital has resulted in a revival of old media, such as printmaking, handmade films, and audiocassettes, and the increased use of analogue devices such as cameras and non-digital keyboard instruments.

One complaint of the so-called digital revolution is the use of digital technology to standardize and normatively reduce, control or eliminate errors and failures. This "high tech, high fidelity cleanliness" (Cramer 2014), which some believe is a primary theme of digital technology, has been criticized by many in the arts community. Computer music specialist Kim Cascone (2000) noted that while failure is an inherent part of the creative process, digital culture controls and suppresses it rather consistently.

With electronic commerce now a natural part of the business fabric of the Western world and Hollywood cranking out digital fluff by the gigabyte, the medium of digital technology holds less fascination for composers in and of itself ... the medium is no longer the message; rather, specific tools themselves have become the message. (393)

Cramer (2014) also suggests that part of this rejection of digital technology is dualistic, with a rejection of both the digital high tech and digital low quality. From this standpoint, there is inherent value in traditional media that simply does not exist in the same way within digital media due to the perception that digital media is more easily and more quickly achieved.

Clements, Ann. 2018. A postdigital future for music education: Definitions, implications, and questions. Action, Criticism, and Theory for Music Education 17 (1): 48-80. doi:10.22176/ act17.1.48 
Consider for example the persisting argument that vinyl LPs sound better than CDs (let alone MP3s); that film photography looks better than digital photography (let alone smartphone snapshots); that $35 \mathrm{~mm}$ film projection looks better than digital cinema projection (let alone BitTorrent video downloads or YouTube); that paper books are a richer medium than websites and e-books; and that something typed on a mechanical typewriter has more value than a throwaway digital text file (let alone e-mail spam). In fact, the glitch aesthetics advocated by Cascone as 'post-digital' are precisely the same kind of digital trash dismissed by 'post-digital' vinyl listeners. (para 15)

Another potential drive away from digital technology use may be society's general boredom with what Snodgrass (2014) defines as the banality of the digital. "In the face of its own unsettling anamorphic alterity and obsolescing drive, the digitally inflected subject has shown an impulsive readiness to latch onto the banal" (para 19). The mainstreaming of user generated content, such as memes, which can be easily seen on most late-night talk shows and other mass media sources, have resulted in societal digital saturation that reduces interest and meaning. As an example, Snodgrass discusses that the analogue of filters on Instagram images, that make alterations to pictures easy and nearly fool-proof, result in little more than artificiality. Snodgrass believes that while the users may place aesthetic value in the fauxstalgia images, this invasive technification includes a degree of banality that, for some, is too difficult to ignore. He concludes that the creation of sameness and falseness, particularly by for-profit entrepreneurial companies deliberately pushing that market, is steering many away from mainstream artistic digital consumption.

While digital technology has offered incredible liberation for creative output based on ease-of-use and a reduction of technical skills required for creation (at least in some mediums) the design and interface of these technologies have also added algorithmic prescription to the process. A longstanding complaint about digital technology use within the arts is that the creative process through which users can engage with and through them is predetermined by their design and interface. World-renowned designer Milton Glaser is quoted as having said "computers are to design as microwaves are to gourmet cooking" (Schneider 2014, para 4). His long-standing disapproval of the computer as a primary design tool stems from his acknowledgement that "the idea of drawing as a discipline that is necessary for the practice of design, has just about vanished" (Glaser interview in Shalat 2001, para 9).

Clements, Ann. 2018. A postdigital future for music education: Definitions, implications, and questions. Action, Criticism, and Theory for Music Education 17 (1): 48-80. doi:10.22176/ act17.1.48 
This is not to say that computers are not present in his studio, he acknowledges that they are an industry standard, however he himself does not use computers and requires his students to develop their ideas prior to using the computer, at which point the computer is used simply to test ideas and not as a platform for creation. Glaser believes that the main problem with the computer is that it makes everything too clear instantaneously. He believes that drawing consists of 70 percent looking and 30 percent technical drawing on paper.

The difference between the brain and the computer has to do with the way the brain works by maintaining its fuzziness. You do a sketch-which is why, incidentally, I think that drawing is essential-and the brain examines the sketch and modifies it. The brain then thinks of another idea. And then you do another sketch, which is still fuzzy, and there's a response on the part of the brain, and you move in a series of steps toward clarification. The maintenance of ambiguity is a central part of how the brain works. (Shalat 2001, para 13)

The challenge of beginning with computer design programs, for Glaser, is that they can inadvertently encourage weak ideas to become well-developed, that they prescribe the ways in which you view your own work, and, similarly to the "cleanliness" issues describe in music production discussed above, design programs provide too regulatory of a view of potential options for modification.

Another issue, in line with Glaser's thinking, is that it is becoming increasingly difficult for artists to self-select to engage or not engage in digital technology use. VanMeer (2013) reports that the majority of bachelor's students in art schools in the Netherlands preferred making a poster to creating a website, if they had the ability to choose. That these young artists and designers have a preference for non-digital techniques, at least for particular tasks, challenges the assumption that because artists are frequently surrounded by digital technologies that there is an inherent desire to use them. This data also creates room for the idea that arts education, unlike other disciplines of schooling, may desire a more flexible relationship with technology than other school subjects.

\section{Implications for Music Education}

In music and music education it is not uncommon to hear arguments against the use of technology, particularly the perception that digital instruments and instrumentation are an inauthentic or undesirable aspect of musical practice and that recordings are less desirable than live performance. These ideas are preva-

Clements, Ann. 2018. A postdigital future for music education: Definitions, implications, and questions. Action, Criticism, and Theory for Music Education 17 (1): 48-80. doi:10.22176/ act17.1.48 
lent in professional music circles and, as a result, have residual influence in musical study at a variety of levels, particularly within ensemble settings.

In August, 2014, a performance of Richard Wagner's four-opera Ring cycle was postponed after it was revealed that the producer intended to accompany the singers with sampled instrument sounds played by a computer (Pogue 2014). Musicians and music lovers argued that live orchestras are essential and that "nobody buys a ticket to listen to a CD" (para 8). Yet, despite these sentiments, a musicians strike in 1993 (a full 20 years earlier), at the John F. Kennedy Center for Performing Arts in Washington D.C. announced that its production of the Phantom of the Opera would use taped accompaniment and $90 \%$ of the ticket holders attended anyway (Pogue 2014). This implies that despite the musicians' insistence that audience demand live players, evidence suggests that it is difficult to tell the difference between a live but amplified orchestra and a sampled one. The real difference is the knowledge of whether or not playing musicians were present, which may have more to do with tradition, nostalgia, and an economic desire to see musicians employed than sonic or aesthetic elements, demonstrating that the use of digital technology in some music performances remains highly controversial.

In May 2016, an article about Tim Harte, an incoming freshman at the University of Missouri-Kanas City, Conservatory of Music (Chen 2016) enlivened opinions on social media as it was announced he was the first student accepted into the Conservatory with computer laptops as his primary instrument. While Harte's work does not fall under the category of digitotalitarianism, the reaction to the story, as demonstrated through social media, does. While comments on this story ranged from support to serious concern, the primary argument here is that despite over twenty years of digital musical engagement, coupled with a large and growing number of music creators and players for whom digital technology is their main musical medium, there is still debate on whether or not digital musicing is legitimate enough to study along traditional instruments within a conservatory model.

In many settings, music teacher education programs are regulated by a number of certifying agencies at the state and national level that regulate the kinds of courses offered and required. These regulations coupled with the musical values inherent within the schools of music in which music educational programs typically reside are often traditional instrument-centric, with some very notable, yet

Clements, Ann. 2018. A postdigital future for music education: Definitions, implications, and questions. Action, Criticism, and Theory for Music Education 17 (1): 48-80. doi:10.22176/ act17.1.48 
few, exceptions. Additionally, part of this challenge may be based economically on the large number of studio music faculty employed in American schools of music, with a perceivably small number of those faculty having the skills needed to teach digital instruments or having a desire to do so. With digital tools changing so rapidly, it is difficult for musicians to stay on the cutting edge while also maintaining mastery on their instrument of choice. Digital technology teaching is often viewed as "someone else's area" and it is not prolifically taught throughout most curriculums.

Resistance to digital technologies may not just be a matter of preferences and instead may be a result of levels of technological development that do not cater well to our own methodological preferences and practices. For example, American music education is deeply tied to kinetic whole-body engagement, motion, and movement. This connection is evident in nearly every popular general music approach and multiple approaches within ensemble settings. The use of music applications (or apps) through a touch screen device or tablet, which has become a fairly typical application of digital technology in many pre-kindergarten through high school music classrooms, often reduces kinetic musical engagement to percussive screen tapping. This is not to say that meaningful musical encounters are not present, certainly from a creativity standpoint, but that current digital technology does not always allow or encourage full body engagement often thought of as a foundational element of music education practice.

While some of this is simply a challenge of expansion, modernization, and catching up with digital tool use and digital tools catching up with musical practice, questions remain concerning how skepticism and distrust of digital music making coupled with nostalgia for what we have done well for so long may be effecting our slow progress towards full acknowledgement of the digital era, let alone the proposed postdigital era. This leaves several questions for consideration:

- To what extent are current music education practices bound by the perception that quality musical performances are those done by traditional instruments in non-digitally or limited digitally enhanced ways?

- To what extent has the field of music education embraced the digital era, at least to the extent that other arts disciplines have, and what effect, if any, has this had on music teaching and learning?

Clements, Ann. 2018. A postdigital future for music education: Definitions, implications, and questions. Action, Criticism, and Theory for Music Education 17 (1): 48-80. doi:10.22176/ act17.1.48 
- Is the field of music education at risk of providing overly prescriptive or oversimplified compositional and performance tasks through digital technology tools?

- Has the field of music education been effected by the concepts of digital cleanliness or overly prescriptive digital interfaces that may negatively impact creative processes?

- Is there a current feeling of disenchantment with digital systems and media gadgets within the field of music education and, if so, how might this effect the future use of digital technology tools in music classrooms?

- What role, if any, has banality or technification played in the rejection of or disenchantment with digital technology use by some within the fields of music education?

\section{Construct 2: Digital Expansion}

But lo! Men have become the tools of their tools. (Thoreau 1854, 37)

The construct digital expansion consists of perspectives that acknowledge that society's engagement with digital technologies may no longer be novel, but that a separation from digital technology is not only undesirable, it is impossible as new digital technologies will continue to evolve resulting in the reshaping of culture and society. "Whenever we shape technology, it shapes us both individually and as a society. We created cars and cars turned us into motorists, auto mechanics, and commuters" (Frauenfelder 2016, para 2). Relating to the theory of technological determinism (believed to have been coined by Thorstein Veblen) this construct presumes that society's digital technology drives the development of social structures and values. Application of this construct to the digital age implies that the digital revolution has not ended and will not end in the foreseeable future. These perspectives focus on the continuation of digital technology as tools recognizing that the ways in which humans engage with these tools effects tool production and human output equally.

For many artists working and creating through digital technology, there is no longer an ability to separate the digital from the real-world. Differing from digitotalitarianism, which often seeks to separate traditional practices from digital technologies based on values or aesthetics, approaches within the digital expansion construct imply that a separation is not desirable and not possible. While

Clements, Ann. 2018. A postdigital future for music education: Definitions, implications, and questions. Action, Criticism, and Theory for Music Education 17 (1): 48-80. doi:10.22176/ act17.1.48 
nostalgia may continue to exist, separating modern artistic practice from its intermingling with digital technologies is simply unfeasible in some fields.

Post-digital architecture is not architecture without any digital component ... [it is] an architecture that is very much a synthesis between the virtual, the actual, the biological, the cyborgian, the augmented and the mixed. It is impossible, anymore, to talk of digital architecture as a binary opposition to normal realworld architecture. (Spiller 2009, 95)

This reflection is important in that it emphasizes that prior digital dualisms between the virtual and real and between the digital and biological are no longer the case in this field. Synergy among these facets has become a hallmark of the postdigital era for those associated with the digital expansion construct. It implies that output is made better through the combination of human creative attributes and digital technology components that enhance production capabilities.

Embracing the creative possibilities of digital technology, music composer Cascone (2000) states that admittance and exploration of technologies' imperfections and errors have led to a new postdigital aesthetic that embraces the "glitches." She found that the essence of non-purposeful technological noises has become their own kind of aesthetic that provides fertile materials for new creation.

The 'post-digital' aesthetic was developed in part as a result of the immersive experience of working in environments suffused with digital technology: computer fans whirring, laser printers churning out documents, the sonification of user interfaces, and the muffled noise of hard drives. But more specifically, it is from the 'failure' of digital technology that this new work has emerged: glitches, bugs, application errors, system crashes, clipping, aliasing, distortion, quantization noise, and even the noise floor of computer sound cards are the raw materials composers seek to incorporate into their music.

David Sabel, Chairman and CEO of Young and Rubicam, the worlds tenth largest advertising agency specializing in digital and social media, direct marketing, and brand identity, clearly stated his concerns about the concept of postdigital in a blog posting entitled $A$ "Post-Digital" World, Really? (2012).

The truth is we are only at the very beginning of what's digital ... a bigger truth is that while digital is everything, everything is not digital. And, in fact, it never has been, nor will be...

We are beginning to take everything we've learned from the digital world and bridge it back to the physical world. Because lo and behold, that's where people live. (para 2-3)

Clements, Ann. 2018. A postdigital future for music education: Definitions, implications, and questions. Action, Criticism, and Theory for Music Education 17 (1): 48-80. doi:10.22176/ act17.1.48 
Unique to the digital expansion construct is the perspective that technology influences and shapes society and social values-and, not necessarily, the other way around. This idea is critical in that while it accounts for the after effects of use and engagement with digital technologies as tools, it does not purposefully focus on the ethical impacts of human engagement with digital technology over time, nor does it consider any obligation we may have in creating digital technology that represent society's values, beyond an attempt to create meaningful tools, or the development of tools that attempt to intentionally better these values. Using the phrase Digital Exponential, Sabel believes that "because we are finding exponential value of digital [technologies] in the real world" (para 5) that they must be connected to human purpose, not values, to be successful.

We used to talk about living online and offline. But more and more, we are creating seamless paths between the two, creating a complete lifestyle, enriched and enabled by technology rather than engulfed by it. (para 6)

Done right, Digital Exponential is far more compelling than 'post-digital.' Who wants to live in a world where, as one pundit put it, 'digital is becoming like air: the only time you'll notice it, is when it's not there?' Not me. I look at some of the really interesting things happening today, many of which are happening on mobile, and I see how they bridge the digital and the real world. And that's what I want to see more of when I look forward to future technologies. (para 8)

The primary challenge to the digital expansion construct is that digital technology continues to be viewed as a tool to enrich or enable and it does not take a deeper look at the depth of impact engagement with these tools has on being human. It also does not consider the purposeful creation of new digital technologies to not only serve as tools but to purposefully reshape and enlighten society and culture. It does not investigate the relationship between tool use and being human comprehensively and it views only the perceived helpfulness that digital technology tools have to offer.

\section{Implications for Music Education}

The plethora of digital technology-based music tools make once complex tasks such as music production and transcription literally child's play. Digital musical tools can be easily understood and utilized by music educators to expand musical capabilities for novice and advanced students alike. This leaves little doubt that digital technology has expanded the repertoire of and approach to teaching music

Clements, Ann. 2018. A postdigital future for music education: Definitions, implications, and questions. Action, Criticism, and Theory for Music Education 17 (1): 48-80. doi:10.22176/ act17.1.48 
within schools that have access to it. What used to cost tens of thousands of dollars, such as recording equipment, can now be purchased inexpensively as a mobile application (or app) that takes very limited training to use.

The number of music apps being produced, downloaded, used, and the length of their usages is continuously on the rise (Dogtiev 2015) and it is highly unlikely that there will be a decrease in digital music app production or use for some time. This data makes it tempting to rebuke the concept of a postdigitial paradigm based on the idea that when use is ever increasing how can we be "post"-digital?

The depth to which digital technologies are impacting music teaching and learning is evident by examining modern commercial texts aimed at music instruction. Textbook companies, who are driven by sales and profit, cannot afford to make errors in estimating digital technology's popularity and use by teachers. As such, they serve as, at least, a market indicator for digital technology use within the field and, at most, a prediction for continued growth within the field. The longstanding Macmillan McGraw-Hill basal textbook series Spotlight on Music $\odot$, for general music classes pre-kindergarten through eighth grade, is phasing out paper textbooks in favor of a completely online digital teaching and learning system. While it is unknown if this decision has been driven by teachers' desire for digital enhancement and engagement or simply as a cost-effective alternative to print copies and in response to copyright technicalities on owning verses streaming musical examples, it will result in significant changes in the delivery of instruction including the ways in which music classrooms who utilize these products will operate. This leads to several questions about the impact that digital expansion may have on music education.

- Digital expansion is built upon the concept that a separation from digital technology is not desirable and not possible. To what degree is the field of music education able to separate from digital technologies and is that ever desirable?

- Is it possible to untangle music education from digital technology, if we wanted to? Or are we, like modern architecture, bound to forever have a cyborgian approach through a mixture of digital technology and more traditional modes of making and doing music?

- Does the answer to this question change based on the style of music course being offered (i.e., traditional performance-based, alternative performance-based, general music, etc.)?

Clements, Ann. 2018. A postdigital future for music education: Definitions, implications, and questions. Action, Criticism, and Theory for Music Education 17 (1): 48-80. doi:10.22176/ act17.1.48 
- Or, do we not have as much untangling to consider as we never intertwined digital technologies in music classrooms as heavily as other artistic fields or out-of-school musical practices?

- How important is the concept of bridging digital practices to non-digital practices within music education settings? Is that the best direction for change to flow?

- To what degree and in which ways does digital tool use impact engagement in the processes of music teaching and music learning?

- Does repeated practice in using digital musical tools ultimately affect the ways in which we musically engage with our own ideas and each other?

- In which ways is music education broadened and limited by the digital tools to which we have access?

\section{Construct 3: Digital-Cultural Hybridity}

What does it mean to be human in an age of machines, and can we coevolve? (Frauenfelder 2016, para 4)

The density of the interrelationship between digital technology production and human engagement with digital technology often leaves us trying to determine which side is truly in control of the exchange. The digital-cultural hybrid construct is rooted in the perspective that we often underestimate the accommodation of technology within our lives and that "digital is disappearing into use" (Childs 2015, para 4). Unlike the digital expansion construct, that is based on digital technology's impact on society, the digital-cultural hybridity construct acknowledges that the relationship of change flows both ways. Evolutionarily, technology creates us as we create it. We are equally changed by our engagement through technology as we change technology to suit both our needs and our values. The paradigm of digital-cultural hybridity attempts to move beyond the creation and use of digital tools simply because of their newness or perceived helpfulness in terms of productivity, towards a focus on building and using digital tools that are intentionally encoded with values and principles that ensure equality and inclusivity and that optimize for symbiosis of digital and human.

While humans create digital technology, it is frequently consumerism, innovation as externality for economic advantage, and corporate profit-making, that drive digital technology invention. In the mid-nineteenth century economist Joseph Schumpeter (as quoted in Grupp 1998, 53-4) established innovation as a questions. Action, Criticism, and Theory for Music Education 17 (1): 48-80. doi:10.22176/ act17.1.48 
key factor of economic development. Schumpeter asserted that capitalism "not only never is, but never can be stationary," and that its movement is driven by new products, new manufacturing and new distribution techniques (Schumpeter 1942, 82-3).

The economic study of digital technology production developed two linear models, "technology-push" and "demand-pull," and one non-linear model, "technological trajectory” (Dosi 1982, 147). These models highlight the complexity surrounding the interrelationship of digital technology production and user needs and engagements. The technology-push model is underpinned by the idea that science changes society. This model can be illustrated by a line of influence passing from scientists, through technologists and marketers to users, where the chain of influence is exerted (MacKenzie 1996, 24). This means that the digital innovation is not a result of an established demand in the market, but, instead, it is pushed towards the user in the expectation that it will satisfy an as-yet unmanifested need.

The demand-pull model of innovation rearranges the line of influence so that it begins with market needs and passes through research and development before reaching the manufacturing process, and finally, users (Dosi 1982, 149). Factors which may create a demand-pull scenario are often rooted in social trends, revolving around anticipated advantages to the user, whether in product or service design, or in value for money. Non-user-centric variables such as competition, supplier or distributor demands and internal motivations including risk reduction are also contributors. Demand-pull innovation often relies on in-house research and development departments. While demand-pull places perceived users' needs at the beginning of the development process, it and technology push are dependent on capitalist non-user variables, such as cost and marketability, for production.

Dosi (1982) suggested an alternative theory of innovation, based upon "technological paradigms" and "technological trajectories." He recognized that both the push and pull models discussed above, restrict innovative possibilities. Dosi's trajectories take into consideration that technological development is often nonliner and that it relies on recognized limitations and envisaged economic rewards. Unlike the liner models, this model is shaped by socio-economic factors and social-cultural environments in two specific ways: firstly, development is aimed in the direction of anticipated economic advantage, and secondly, the market de-

Clements, Ann. 2018. A postdigital future for music education: Definitions, implications, and questions. Action, Criticism, and Theory for Music Education 17 (1): 48-80. doi:10.22176/ act17.1.48 
cides if the technology survives. Within this model there is greater flexibility for innovation as, ultimately, it is the users that determine if new technologies are of value.

The depth of complexities surrounding the relationship of digital technology use in human life become even more compelling when we consider that these technologies are often optimized for symbiosis. Russell Davies (2011) who has been featured in publications such as the Guardian newspaper as a "postdigital pioneer" argues that his application of the term postdigital was created to encourage technologists and business people to get past their inflated egos too often attached to extreme technological use.

They thought they were the end of the revolution, they'd stormed the Winter Palace and they were starting to tidy up. Post Digital was a suggestion that, maybe, we needed to get over that and start thinking about the next phase, the phase where it got integrated into the world. What will we do, I was asking, when we can take all this connectivity for granted? When it's no longer special or interesting? What will we build then? (para 8)

Two important characteristics are apparent in Davies definition. First is the notion that we have begun to take digital technologies for granted. In essence, this means we can stop hyper-focusing on the newness and innovation of digital technologies and turn our attention instead towards the value of meaning and use. Secondly, he postulates that underlying innovation, is the deliberate intention of making technology meaningful in the world; the idea that building is only important when it is integrated into societal needs and wants, frequently beyond the concept of a tool.

McLuhan, in the landmark text, Understanding Media: The Extensions of Man (1994) theorizes that there comes a point when tools become so incorporated into our sense of self that they become an extension of our bodies similar to a prosthesis. For centuries, we have populated our world with machines that help us to do things we cannot or do not want to do ourselves. Within the digital era, our world has become so saturated with machines that they have faded into the background to the point where we are at risk of not fully noticing them or the degree to which they are changing us as individuals and as a society. "We're entering an era where fifty billion machines are in constant communication, automating and orchestrating the movement and interactions among individuals, organizations, and cities” (Frauenfelder 2016, para 2).

Clements, Ann. 2018. A postdigital future for music education: Definitions, implications, and questions. Action, Criticism, and Theory for Music Education 17 (1): 48-80. doi:10.22176/ act17.1.48 
The Institute for the Future (IFTF), a non-profit think tank in Silicon Valley that explores "long term future plans to make better decisions in the present" (Frauenfelder 2016, para 3), has completed research on how machine automation is becoming an integrated, embedded, and an ultimately invisible part of virtually every aspect in our lives. The motivation for their research comes from a desire to move beyond the debate over whether or not humans are in a "zero-sum race against machines" (para 4) and, instead explore a future of human-machine symbiosis. They believe doing so would move the conversation to a place where humans and machines can coevolve together.

As we design new things, new services, and new experiences with technology, how can we design those with principles that optimize for symbiosis? Right now, a lot of our machines and technology experiences are encoded with notions of productivity, efficiency, and optimization, but different possibilities open up when we think about encoding those systems with values and principles that ensure equity and inclusivity. (Rod Falcon in interview within Frauenfelder 2016, para 5)

In June 2009, the 52group gathered from across the higher education sector to consider the confluence of education and digital technology. The resulting paper entitled Preparing for the Postdigital Era provided one of the most humanistic definitions of the term postdigital. Arguing that the speed of change resulting from dramatic digital innovation has left society falsely believing that social change was created by the digital rather than being constructed by humans within digital space. They determined that this error has placed digital dialogue on the wrong side of the technology and human equation. They predicted that in the postdigital era educational tools would reach a point of transparency. This fading of digital technology from foreground to simply being a component of modern teaching and learning creates significantly less interest in the tools of technology and refocuses on technology's colonization of people's lives. In this vision, technology simply is and simply works:

As the 'digital' calculator and the 'digital' watch have become calculators and watches, so will the ebook become a book and IM become 'message': the 'instant' will be taken for granted. Things digital will be accepted alongside our other technologies and the slate swept clear of many of the distracting dualisms (and technological factions) that pervade the educational discourse.

The postdigital frees us to think more clearly and precisely about the issues we face, rather than become tied to an obsession with, and the language of, the new. It allows us to take a broader approach to the challenges and opportunities

Clements, Ann. 2018. A postdigital future for music education: Definitions, implications, and questions. Action, Criticism, and Theory for Music Education 17 (1): 48-80. doi:10.22176/ act17.1.48 
we face. Removing the focus on the digital leads us to see the division between the 'digital' have and have-nots not in terms of their lack of access to digital technology, but in terms of their lack of access to economic, social and political power. (para 3)

Taffel (2015) is in agreement with the intended departure away from the importance of newness in technology and believes that by focusing media on the ever-accelerating time frame of software and hardware development, we are distracting ourselves from the reflective and critical scholarship needed to evaluate cultural potentials. "The postdigital is a call to action to abandon the fetishization of the new, which is clearly present in calls to move onto the next big thing, and to instead embrace scholarship focused upon performativity shaping social structures along more egalitarian lines" (7).

The relationship between digital technology and human engagement is continually changing, particularly in the arts where creativity and ingenuity provide fertile ground for advanced exploration of how far technology can develop. Unlike digital expansion, which focuses on bringing lessons learned through digital technology into society, the cultural-hybridity construct is based on perspectives that encourage us to critically explore how technology, created by humans, affects the human to digital technology relationship and humanity overall. It also intends to reduce the focus on digital technological innovation for the sake of newness and to purposefully create technology that acknowledges or even betters the values of humanity.

Iamus, a computer cluster powered by Melomics technology and housed at the Universidad de Malaga in Spain, has been programed to compose full musical compositions that can be played by human musicians. The average time Iamus takes to compose a full score is one second (Wilkins 2013). In 2013, nine songs composed by Iamus were recorded by the London Symphony Orchestra and distributed as the self-titled album Iamus. The algorithmic coding instructing the computer to write musical scores is a milestone in the linkage between technology and music. An offshoot of artificial intelligence, the project uses evolution as its basis with each composition consisting of a musical core that becomes increasingly complex and evolves automatically. The activity is controlled by an algorithm inspired by biological processes. "Just as human genomes mutated over time to create a multitude of unique people, Iamus alters and rearranges its source material to create complex pieces of music. The only restrictions placed on

Clements, Ann. 2018. A postdigital future for music education: Definitions, implications, and questions. Action, Criticism, and Theory for Music Education 17 (1): 48-80. doi:10.22176/ act17.1.48 
its output are determined by what can be realistically played by a musician and their instrument" (Smith 2013).

Project Magenta, launched by Google in 2016, aims to explore if machine learning can be used to create compelling art and music. Developers are particularly interested to know if the program can advance machine intelligence through the development of algorithms tied to the creative generation of art and music content. The project is being built on an open source infrastructure in order to build a community of artists, coders, and machine learning researchers.

The response to Project Magenta by professional musicians thus far is interesting. Some have acknowledged that the impact of the project will remain unknown until wide-scale artists and musicians can access it. Others, like Peter Swendsen, a professor of computer music and digital arts at Oberlin, observe that "software comes and goes in weeks sometimes" (in McFarland 2016, para 12), suggesting that the general instability and typical short lives of technological tools may affect the reach of the program. Others are predicting that this project has the potential to forever change the music industry. David Cope, a retired professor at the University of California-Santa Cruz and pioneer in computer generated music, believes it is inevitable that artificial intelligence will be widely used by the best composers to aid their work. According to Cope, "it's going to rampage through the film music industry ... just as cars happened and we didn't have the horse and buggy anymore" (in McFarland 2016, para 9).

The line between digital tool and artistic process is quickly morphing. Music and the arts have been one of the last frontiers to be explored by advanced computing due to the complex nature of creative art making. Automated web design programs and robots that paint quality forgeries of interesting art pieces, point to the possibility that machines are becoming a creative class (Smith 2013). "Whether they're designing websites on their own or creating their own art, machines and automation are moving into the creative artistic realm, and it's an area we're going to have to contend with. We need to be open to thinking about how can we create new music and new art with machines" (Falcon in Frauenfelder 2016, para 23).

Perspectives within the construct of digital-cultural hybridity remind us that not only does digital technology use have the ability to shape individuals and society, but that we should be mindful in what technologies we develop and how they are developed, focusing on those that have the most potential for addressing

Clements, Ann. 2018. A postdigital future for music education: Definitions, implications, and questions. Action, Criticism, and Theory for Music Education 17 (1): 48-80. doi:10.22176/ act17.1.48 
human values. As Davies (2011) predicted, we have begun to take digital technologies for granted which allows us to turn our attention towards the value of digital technology's uses and the meaningfulness of these engagements. According to this construct, the end goal should be to foster a digital technology to human symbiosis.

\section{Implications for Music Education}

In many music education settings, digital music gadgets and apps continue to inspire teachers and students alike. The overall novelty of digital devices, such as tablets, and the concept that these devices can be musical has become mainstream. As such, I suggest that the time has come to shift attention within our field away from a hyper-focus on the latest and newest technologies towards a critical exploration of how pedagogical approaches to teaching music have been altered or expanded through digital technology use. Understanding our use will help us to determine if our approaches match underlying values within the field. Not that the creation of new tools is in some way passé (many would say it is just the opposite), but I suggest that we move forward with a critical perspective of what these tools contribute to and disrupt. Digital technology programs such as Iamus and Project Magenta will continue to expand, solidifying the relationship between digital technology and artistic practice. As a field that develops future musicians, we should be proactive in the forefront of technological advancement, working to shape the tools and engagement practices of modern musical doing and making.

The digital-hybrid construct emphasizes the interconnections of digital technology's influence on changing society and society's intentional creation and purposeful implementation of useful technologies that take into consideration humanistic values. This brings to light several questions for contemplation in the field of music education.

- How do we balance the unique characteristics of music-based digital technology with the affordances of human artistic practice, knowledge, and skills? And what should be the roles of each moving forward?

- What are some of the major music technologies that are shaping the future of our field and are these technologies being used as a force for change and possibility? What is the probability that these technologies

Clements, Ann. 2018. A postdigital future for music education: Definitions, implications, and questions. Action, Criticism, and Theory for Music Education 17 (1): 48-80. doi:10.22176/ act17.1.48 
can open unexpected and unprecedented opportunities for equality and inclusiveness? Are we hitting the mark or falling short?

- How do we balance high-tech digital programs and approaches in music education while maintaining traditional artistic practices?

- What role or roles should music educators play in the development of advanced digital tools, programs, and approaches to technological use in order to ensure our values and priorities are being met?

\section{Conclusions on a Postdigital Era}

The complexities expressed in Ryan J. Nicholson's photo essay (as discussed at the beginning of this article) illustrate the challenges surrounding the intersections of artistic endeavors and the advancement of digital technology. Unlike the digital era, which is relatively easy to define as the shift from traditional industry to an economy based on information computerization, the postdigital era, if it exists, is a much messier consideration. It is a combination of both complimentary and contrasting perspectives from across a wide array of disciplines.

As evident by this discussion, it may be impossible to determine a single definition of the term postdigital that is broad enough to cover the breadth of postdigital ideologies and applications. However, the three constructs provided here may be enough to begin serious dialogue and discussion regarding the various possibilities for a postdigital future for music education.

The construct digitotalitarianism shared the perspectives of disenchantment, boredom, banality, and frustration with the prescriptiveness of digital tools and technologies. Predetermined interfaces, algorithmic enhancements, and simple ease-of-use without the previously required technical skills of traditional artistic approaches all have the ability to impact the arts. The reduction of failure and the narrowing of approach through standardized interfaces have resulted in a perceived loss of creative skill. Perceptions that digitally created or enhanced art and music are not real, or at least are not desirable or of quality, are prevalent among certain circles both within and outside the arts. Artistic practice has a long and important history of physical art making, of creating and playing music on skill-bound traditional musical instruments, and working with 3 dimensional tools and materials. Music and art made solely through digital technologies may represent the loss or narrowing of important skills and a resulting change in

Clements, Ann. 2018. A postdigital future for music education: Definitions, implications, and questions. Action, Criticism, and Theory for Music Education 17 (1): 48-80. doi:10.22176/ act17.1.48 
mindset among creators. Making and playing physical things "takes patience, physical skills, coordination, and the maturity to deal with failure and difficult challenges" (Hunt 2013, para 5). Musicians who create and perform through digital technology are frequently considered outsiders in many higher education environments, perpetuating the perspective that musical value lies primarily in traditional practices or that there should remain a purposeful separation between traditional practice and digital technology use.

The construct digital expansion is based on the perspectives of those that believe a separation of society from engagement with digital technologies is impossible and undesirable and that, to some degree, the digital revolution is not over as new digital technologies will continue to evolve. Key to this construct is the idea that digital technology drives the development of social structures and values and that digital tool-use defines who we are as individuals and community. A stumbling point for digital expansion includes confusion about the term post-, especially given the acceleration of digital technology creation and use. A challenge to this construct is that digital expansion continues to place a high focus and regard on digital tools; and while there is acknowledgment that digital technology changes society, it lacks any in-depth examination of the impact engagement with these tools has on being human.

The construct digital-cultural hybridity represents a perspective that over time we have focused too heavily on the development of digital technology tools and their uses without critically exploring if these engagements are positively impacting us as individuals and societies. It also emphasizes that critical reflection should be given to the front end of digital technology development and that a priority should be given not just to digital tools that make life easier, but to technologies that make life better for us as human beings. This perspective highlights that building new digital tools is only important when it is integrated into societal wants, needs, and values. From this perspective, as new digital technologies are created, we are simultaneously recreating ourselves as humans. As such, we need to move towards a symbiosis between digital technologies and humanity in order to co-evolve together.

The greatest achievement of humanity may very well be our ability to develop creative solutions to the problems that afflict us, and it is through abstraction that these solutions are devised. The combination of human creative thinking through the arts combined with ever-increasing capabilities afforded through

Clements, Ann. 2018. A postdigital future for music education: Definitions, implications, and questions. Action, Criticism, and Theory for Music Education 17 (1): 48-80. doi:10.22176/ act17.1.48 
digital technology may be a key to unlocking individual and communal potential in solving many of the world's most perplexing problems. Perhaps, within a postdigital era, music education combined with digital technologies will create a cyborg of advanced creative thinking capable of elevating society's values and resulting in the betterment of life on this planet.

As Stiegler (1998) proposed, the decisions we make about the digital technologies we choose to design, build, and use, along with how, when, and for how long we engage with them, may have long lasting implications within our field. Questions concerning the intentionality of digital technology in relation to music education's culture and values must be critically considered and questioned in order to move forward in any kind of symbiotic relationship with the digital tools we use. A potential postdigital future may mean different things to different people. To some music educators it will result in a purposeful reduction in use of digital technologies accompanied by a return to older humanistic mediums. To others it will require the need for continued expansion of digital tools, techniques, and approaches. And yet, to others still, a postdigital future is a reduction of the hyper focus on digital technology as tools and a movement towards a digital-cultural hybridity that places human needs and social values above digitaltechnology production without deigning its presence and importance.

As a field, when, how, and where music education resides within a possible postdigital future or futures is up to us. At the local level, we must consider how we engage with our students in music classrooms, ensembles, and teacher preparation programs. At the national and global levels, we must consider the kinds of inquiry and research done on topics related to digital technology use (and to what audiences these discoveries are shared). Purposeful decision making about our future(s) requires an investment in determining what practices, artistic engagements, pedagogies, and content are of most value to our field and how these values can or cannot be addressed through digital engagement. The questions provided within this article serve as an introduction to dialogue about music education's potential postdigital future.

\section{About the Author}

Ann C. Clements is an associate professor and area chair and graduate program chair for Music Education at the Pennsylvania State University. Her primary research areas include music participation, game theory as applied to education,

Clements, Ann. 2018. A postdigital future for music education: Definitions, implications, and questions. Action, Criticism, and Theory for Music Education 17 (1): 48-80. doi:10.22176/ act17.1.48 
learning in blended, virtual and augmented realities, and ethnomusicology. Clements has given over 150 presentations throughout the United States and across the globe. She is published in multiple national and international journals and is the author, co-author and editor of several books in the field of music education. Clements has served in leadership and editorial roles in national and international music education and ethnomusicology organizations and currently serves as the Director of the Center for Pedagogy in Arts and Design at PennState.

\section{References}

52group. 2009. Preparing for the postdigital era (Version 0.1). June 17. https://docs.google.com/document/d/1TkCUCisefPgrcG317_hZa4PwZoQ8m 7rL5AJF6PazHHQ/preview

Abrahams, Frank. 2015. Another perspective: Teaching music to Millennial students. Music Educators Journal 102 (1): 97-100.

Albert, Daniel. 2015. Social media in music education: Extending learning to where students “live”. Music Educators Journal 102 (2): 31-8.

Andrews, Ian. 2002. Post-digital aesthetics and the return to modernism. http://www.ian-andrews.org/texts/postdig.html

Bauer, William. 2014. Music learning and technology. New Directions: A Journal of Scholarship, Creativity, and Leadership in Music Education 1 (1). http://nd.music.msu.edu/music-learning-technology-william-bauer/

Bolden, Benjamin. 2013. Learner-created podcasts: Students \& apps, stories with music. Music Educators Journal 100 (1): 75-80.

Cascone, Kim. 2000. The aesthetics of failure: 'post-digital' tendencies in contemporary computer music. Computer Music Journal 24 (4): 392-8.

Chen, Jen. 2016. UMKC Accepts its first music student whose instrument is the computer. KCUR 89.3 Blogpost. May 12. http://kcur.org/post/umkcaccepts-its-first-music-student-whose-instrument-computer\#stream/o

Childs, Mark. 2015. Post-digitalism-an evolutionary perspective. The Body Electric: Experiencing Technology in Education and Elsewhere, February 4. https://markchilds.org/2015/02/04/post-digitalism-an-evolutionaryperspective/

Clements, Ann. 2018. A postdigital future for music education: Definitions, implications, and questions. Action, Criticism, and Theory for Music Education 17 (1): 48-80. doi:10.22176/ act17.1.48 
Clements, Ann. 2016. Teaching general music in the digital age. In Teaching general music: Approaches, issues, and viewpoints edited by Carlos Abril and Brent Gault, 327-46. New York: Oxford University Press.

Cox, Geoff. 2014. Prehistories of the Post-digital: some old problems with postanything. A Peer Reviewed Journal About (APRJA) 3 (1).

Cramer, Florian. 2014. What is post-digital? A Peer Reviewed Journal About (APRJA) 3 (1). http://www.aprja.net/?page_id=1291

Crawford, Renee. 2013. Evolving technologies require educational policy change: Music education for the 21st Century. Australasian Journal of Educational Technology 29 (5): 717-34.

Davies, Russell. 2011. Again with the Post Digital. Blogpost. http://russelldavies. typepad.com/planning/2011/11/i-first-talked-about-post-digital-at-an-eventcalled-thinking-digital-in-2009-in-gateshead-looking-back-thats-probablywh.html

Dogtiev, Artyom. 2015. App usage statistics: 2015 roundup. Business of Apps. December 14. http://www.businessofapps.com/app-usage-statistics-2015/

Dorfman, Jay. 2008. Technology in Ohio's school music programs: An exploratory study of teacher use and integration. Contributions to Music Education 35: 23-46.

Dosi, Giovanni. 1982. Technological paradigms and technological trajectories. Research Policy 11 (3): 147-62.

Frauenfelder, Mark. 2016. What does it mean to be human in an age of machines? An interview with Rod Falcon. Institute for the Future (IFTF) Blogpost. November 9. http://boingboing.net/2016/11/o9/what-does-it-meanto-be-human.html

Gregory, R. F. 2014. Notes for the Café. New York: Parthenon Books.

Grupp, Hariolf. 1998. Foundations of the economics of innovation: theory, measurement, and practice. Edward Elgar Pub. Cheltenham: UK.

Hammond, Aaron. 2011. Only time will tell if humanity, technology become inseparable. The Oswegonian. April 28. http://www.oswegonian.com /2011/o4/28/only-time-will-tell-if-humanity-technology-becomeinseparable/

Clements, Ann. 2018. A postdigital future for music education: Definitions, implications, and questions. Action, Criticism, and Theory for Music Education 17 (1): 48-80. doi:10.22176/ act17.1.48 
Hansen, Dee, and Sarah Milligan. 2012. At the juncture of research in early reading and music literature. Music Educators Journal 99 (2): 75-80.

Haning, Marshall. 2016. Are the ready to teach with technology? An investigation of technology instruction in music teacher education programs. Journal of Music Teacher Education 25 (3): 78-90.

Hoffmann, Adria and Bruce Carter. 2013. A virtual composer in every classroom. Music educators Journal 99 (3): 59-62.

Hunt, Mark. 2013. Traditional skills are being lost by designers relying on computers. New Statesman. November 4. https://www.newstatesman.com/artand-design/2013/11/traditional-skills-are-being-lost-designers-relyingcomputers

Jassmann, Art E. 2004. The status of music technology in the K-12 curriculum of South Dakota public schools. Ed.D. dissertation, University of South Dakota, United States-South Dakota. Retrieved March 20, 2008, from ProQuest Digital Dissertations database. (Publication No. AAT 3127829).

Macmillian McGraw-Hill. 2016. Spotlight on Music. New York: MacMillian McGraw-Hill Education.

MacKenzie, Donald A. 1996. Knowing machines: essays on technical change. MIT Press. New Baskerville: MA.

Madsen, Clifford, ed. 2000. Vision 2020: The Housewright symposium on the future of music education. Reston, VA: Music Educators National Conference.

McFarland, Matt. 2016. Googles artificial intelligence could transform the way we make music. Chicago Tribune. June 6. http://www.chicagotribune.com/ bluesky/technology/ct-google-computers-creating-songs-project-magenta20160606-story.html.

McLuhan, Marshall. 1964. Understanding media: The extensions of man. Reprint edition. MIT Press.

Mitksza, Peter. 2013. The future of music education: Continuing the dialogue about curricular reform. Music Educators Journal 99 (4): 45-50.

Nart, Sevan. 2016. Software in the technology integrated music education. Turkish Online Journal of Educational Technology 15 (2): 78-84.

Clements, Ann. 2018. A postdigital future for music education: Definitions, implications, and questions. Action, Criticism, and Theory for Music Education 17 (1): 48-80. doi:10.22176/ act17.1.48 
Negroponte, Nicholas. 1998. Beyond digital. Wired, December 1. http://www. wired.com/wired/archive/6.12/negroponte.html

Nelson, Deborah. 2013. Professional notes: Reaching all students via technology. Music Educators Journal 100 (1): 26-9.

Nicholson, Ryan. 2012. Music "Devolution." Photo essay and image posted to Flikr.com May 28. https://www.flickr.com/photos/macmad/7287653144

Ohlenbusch, Grace. 2001. A study of the use of technology applications by Texas music educators and the relevance to undergraduate music education curriculum. D.M.A. dissertation, Shenandoah University, United States-Virginia. Retrieved March 20, 2008, from ProQuest Digital Dissertations database. (Publication No. AAT 3010524).

Portowitz, Adena, Kylie Peppler, and Mike Downton. 2014. In harmony: A technology-based music education model to enhance musical understanding and general learning skills. International Journal of Music Education 32 (2): 242-60.

Pogue, David. 2014. Why digital music looks to set to replace live performances: A scuffle at a Connecticut opera reveals the bleak future of the orchestra pit. Scientific American. September 1. https://www.scientificamerican.com/ article/why-digital-music-looks-set-to-replace-live-performances/

Ratcliffe, John. 1983. Notions of Validity in Qualitative Research Methodology. Science Communication 5 (2): 147-67. doi:10.1177/107554708300500201

Reese, Sam, and James Rimington. 2000. Music technology in Illinois public schools. Update: Applications of Research in Music Education 18 (2): 27-32.

Reyher, Adam. 2014. Idea bank: Popular culture and video games as tools for music learning. Music Educators Journal 100 (3): 16-17.

Riley, Patricia. 2013. Teaching, learning, and living with iPads. Music Educators Journal 100 (2): 81-6.

Rudolph, Thomas. 2004. Teaching music with technology. Chicago: GIA.

Rush, Toby. 2015. Incorporating assistive technology for students with visual impairments into the music classroom. Music Educators Journal 102 (2): 7883 .

Clements, Ann. 2018. A postdigital future for music education: Definitions, implications, and questions. Action, Criticism, and Theory for Music Education 17 (1): 48-80. doi:10.22176/ act17.1.48 
Ruthmann, Alex, Evan Tobias, Clint Randles, and Matthew Thibeault. 2014. Is it the technology? Challenging technological determinism in music education. In Music education: Navigating the future, edited by Clint Randles, 122-38. New York: Taylor and Frances Group.

Sabel, David. 2012. A "post digital" world, really? Thinkwithgoogle.com. May. https://www.thinkwithgoogle.com/articles/a-post-digital-world-really.html

Schneider, Speider. 2014. Was Milton Glaser right about computers destroying design? Webdesignerdepot.com, January 23. http://www.webdesignerdepot. com/2014/o1/was-milton-glaser-right-about-computers-destroying-design/

Schumpeter, Joseph. 1942. Capitalism, socialism and democracy. Routledge Press. London: UK.

Shalat, Andrew. 2001. Designer's Dilemma: To compute or not to compute? Macworld Magazine. March 1. http://www.macworld.com/article/1001986/ 28glaser.html

Smith, Sylvia. 2013. Iamus: Is this the 21st century's answer to Mozart? British Broadcasting Corporation (BBC) News, January 3. http://www.bbc.com/ news/technology-20889644

Snodgrass, Eric. 2014. Dawn to duck: horizons of the digital/post-digital. A Peer Reviewed Journal About (APRJA) 3 (1). http://www.aprja.net/?p=1437

Spiller, Neil. 2009. Plectic architecture: Towards a theory of the post-digital in architecture. Technoetic Arts: A Journal of Speculative Research 7 (2). http://www.intellectbooks.co.uk/journals/view-Issue,id=1752/

Stiegler, Bernard. 1998. Technics and Time Volume 1: The Fault of Epimetheus. Stanford: Stanford University Press.

Taffel, Sy. 2015. Perspectives on the postdigital: Beyond rhetorics of progress and novelty. Convergence: The International Journal of Research into New media Technologies 1 (15): 1-15.

Thoreau, Henry David. 1854. Walden or Life in the Woods. Boston: Ticknor and Fields.

Thwaites, Trevor. 2014. Technology and music education in a digitized, disembodied, posthuman world. Action, Criticism, and Theory for Music Education 13 (2): 30-47.

Clements, Ann. 2018. A postdigital future for music education: Definitions, implications, and questions. Action, Criticism, and Theory for Music Education 17 (1): 48-80. doi:10.22176/ act17.1.48 
Tobias, Evan. 2013. Toward convergence: Adapting music education to contemporary society and participatory culture. Music Educators Journal 99 (4): 29-36.

Van Meer, Aldje. 2013. I would rather design a poster than a website. Willem de Kooning Academy Rotterdam University, 2012-2013. December. $<$ http://www.iwouldratherdesignaposterthanawebsite.nl>, $<$ http://crosslab.wdka.hro.nl/ioi/Co10_folder.pdf $>$

Watson, Scott. 2011. Using technology to unlock musical creativity. New York: Oxford University Press.

Webster, Peter. 2011. Key research in music technology and music teaching and learning. Journal of Music, Technology and Education 4: 115-30.

Webster, Peter. 2016. Creative thinking in music, twenty-five years on. Music Educators Journal 102 (3): 26-32.

Wilkins, Alasdair. 2013. This classical music was created by a supercomputer in less than a second. Gizmodo.com. January 6. http://iog.gizmodo.com/ 5973551/this-classical-music-was-created-by-a-supercomputer-in-less-thana-second

Williams, David. 2014. Another perspective: The iPad is a REAL musical instrument. Music Educators Journal 101 (1): 93-8.

Williams, David, and Peter Webster. 2006. Experiencing music technology (3rd ed.). Belmont, CA: Thomson Higher Education.

Clements, Ann. 2018. A postdigital future for music education: Definitions, implications, and questions. Action, Criticism, and Theory for Music Education 17 (1): 48-80. doi:10.22176/ act17.1.48 